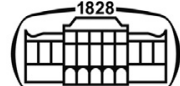

AKADÉMIAI KIADÓ

\title{
Characterisation of the cerebrospinal fluid of horses with West Nile virus neuroinvasive disease
}

\section{Hungarica}

68 (2020) 2, 177-185

DOl:

$10.1556 / 004.2020 .00022$

(C) 2020 The Author(s)

\begin{tabular}{l}
\hline Acta Veterinaria \\
Hungarica \\
\hline
\end{tabular}

\section{ORIGINAL ARTICLE}

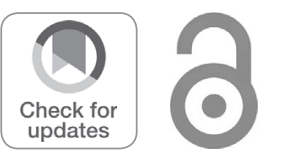

ORSOLYA KUTASI ${ }^{1 *} \odot$, ORSOLYA FEHÉR ${ }^{1}$, SÁRA SÁRDI ${ }^{1}$, NÁNDOR BALOGH ${ }^{2}$, ANNA NAGY ${ }^{3}$, LETICIA MORAVSZKI ${ }^{1}$, EMESE BÓDAI ${ }^{1}$ and OTTÓ SZENCI ${ }^{1}$

\author{
${ }^{1}$ University of Veterinary Medicine Budapest, István Utca 2, Budapest, 1078, Hungary \\ ${ }^{2}$ PraxisLab Kft., Budapest, Hungary \\ ${ }^{3}$ Department of Virology, National Public Health Institute (NPHI), Budapest, Hungary
}

Received: December 15, 2019 • Accepted: March 30, 2020

Published online: September 4, 2020

\begin{abstract}
West Nile virus (WNV) is a zoonotic arbovirus transmitted by mosquitoes between wild birds (natural hosts) and other vertebrates. Horses and humans are incidental, dead-end hosts, but can develop severe neurological disorders. Owing to the close contact of cerebrospinal fluid (CSF) with the extracellular fluid of the brain, the analysis of CSF composition can reflect central nervous system (CNS) impairments enabling the diagnosis and understanding of various neurodegenerative CNS disorders. Our objective was to compare the findings from the CSF samples of horses with neuroinvasive WNV infection with those of healthy controls. We compared findings from fifteen CSF samples of 13 horses with acute WNV encephalomyelitis with those of 20 healthy controls. Protein, particular enzymes and ions, glucose and lactate showed abnormal levels in a significant number of WNV cases. None of the six horses with elevated glucose concentrations survived. Rather neutrophilic than mononuclear pleocytosis was identified with WNV infection. Neutrophils probably play a role in the development of inflammatory response and brain damage. Although elevated glucose levels reliably predicted the outcome, they might be the consequence of increased plasma levels and reflect general stress rather than CNS pathophysiology. The CSF findings of WNV encephalomyelitis patients are non-specific and variable but facilitate the differential diagnosis.
\end{abstract}

\section{KEYWORDS}

equine, cerebrospinal fluid, West Nile virus, encephalomyelitis

\section{INTRODUCTION}

West Nile virus (WNV) is a mosquito-borne zoonotic arbovirus belonging to the genus Flavivirus in the family Flaviviridae (Smithburn et al., 1940) and transmitted in natural cycles between mosquitoes (mainly the genus Culex) and wild birds (Bakonyi et al., 2013; SzentpáliGavallér et al., 2014). Horses and human beings are incidental and dead-end hosts, but severe neurological disorders can develop in horses (Kutasi et al., 2011; Lim et al., 2011). Phylogenetic studies have identified two main lineages of WNV strains. The Hungarian equine WNV outbreak reported in 2008 was the first to be caused by a lineage 2 sub-Saharan strain in Europe. The pathogenicity of this lineage 2 strain resembled that of lineage 1 strains, and its sudden spread was unpredictable (Kutasi et al., 2011; Bakonyi et al., 2013). During the last decade, the epidemiology of WNV in human beings and horses has changed in Europe, with an increasing incidence of West Nile fever as well as of West Nile neuroinvasive disease (WNND) even in more northern regions (Fraisier et al., 2014; Ziegler et al., 2018). 
Depending on the extent of viraemia, WNV can cross the blood-brain barrier and enter the brain, causing meningoencephalitis (Lim et al., 2011). Neurons are targets for WNV infection, and infection in the brain and spinal cord causes destruction and leads to encephalitis and paralysis (Lim et al., 2011). Owing to the close contact of cerebrospinal fluid (CSF) with the extracellular fluid of the brain, the analysis of CSF composition can indicate dysfunctions in the central nervous system (CNS), thereby enabling the diagnosis and understanding of various neurodegenerative CNS disorders (Shahim et al., 2013). To obtain accurate results when evaluating equine CSF samples, besides using a precise sampling technique, the application of correct laboratory analytical methods is also important. However, due to the varied methods that different laboratories use today, it has become imperative for each laboratory to establish its own reference ranges based on the calibrated measurement techniques (Vernau et al., 2008). Until now, very few studies have investigated the association between the imbalance of CSF elements and the severity of WNV infection (Tyler et al., 2006; Fraisier et al., 2014). The aim of the present study was to compare the biochemical and cytological findings of CSF analysis in horses with acute neuroinvasive WNV infections with those of the CSF from control healthy horses.

\section{MATERIALS AND METHODS}

The data were obtained during an observational retrospective case-control study between 2011 and 2016. Since WNND occurs seasonally in Hungary (Kutasi et al., 2011), data were collected between August and November each year. The 20 horses in the control group were sampled simultaneously in the same period. The study was permitted by the Animal Health and Welfare Directorate of the National Food Chain Safety Office (22.1./1606/003/2009).

WNV neuroinvasive cases were defined on the basis of seasonality (August-November), acute neurologic clinical signs (less than 5 days), positive serum IgM ELISA test (IDEXX IgM WNV Ab Test, Hoofddorp, The Netherlands), and the absence of any WNV vaccination in the history. Only clinically healthy horses without any neurologic signs and with haematological and biochemistry parameters within the reference range were included in the control group. In the control group we did not include privately owned horses: the control animals were owned by the university and kept for research purposes in the stables of the clinic and at the neighbouring university teaching farm. Age, breed and sex characteristics of the horses and the sampling sites are described in Table 1.

The CSF of all WNND cases was sampled within $36 \mathrm{~h}$ of clinical admission, and the sampling site was determined on the basis of clinical signs (Table 2). The CSF of horses with characteristics of more pronounced brainstem and cerebral involvement was sampled by atlanto-occipital puncture under general anaesthesia using $1 \mathrm{mg} / \mathrm{kg}$ xylazine iv. (Xylasol, CP-Pharma GmbH, Burgdorf, Germany), 0.02 $\mathrm{mg} / \mathrm{kg}$ butorphanol iv. (Alvegesic, Alvetra u. Werfft $\mathrm{GmbH}$, Vienna, Austria) and $1 \mathrm{mg} / \mathrm{kg}$ ketamine iv. (CP-Ketamin, Produlab Pharma, Raamsdonksveer, The Netherlands) and that of horses with spinal cord involvement was sampled by lumbosacral puncture under sedation with $0.3-0.4 \mathrm{mg} / \mathrm{kg}$ xylazine iv. and $0.02 \mathrm{mg} / \mathrm{kg}$ butorphanol iv. simultaneously with lidocaine (Lidocain-human, TEVA, Debrecen, Hungary) local anaesthesia as previously described (Schwarz and Piercy, 2006). In case of diffuse CNS involvement, both locations were used for sampling purposes, under general anaesthesia. Altogether 15 samples were collected, and two horses underwent both lumbosacral and atlanto-occipital puncture. Within the control group 8 animals underwent atlanto-occipital puncture under general anaesthesia and 12 horses had lumbosacral puncture under sedation.

CSF was first analysed macroscopically for colour and turbidity by placing it in front of a white paper. Samples were centrifuged and stained with Wright-Giemsa within 30 min after collection and another sample from each horse was air-dried after cytocentrifugation and kept for further evaluation. Cytological analysis was performed within $6 \mathrm{~h}$ in all cases. Protein content was measured using an ultrasensitive method, spectrophotometry (Olympus AU400, Beckman Coulter, Hamburg, Germany) and other biochemical parameters like the activities or levels of aspartate aminotransferase (AST), alkaline phosphatase (ALP), glucose, lactate, urea, creatine kinase $(\mathrm{CK})$, lactate dehydrogenase (LDH), sodium, potassium, calcium, chloride, inorganic phosphate, and magnesium were determined spectrophotometrically by the use of commercially available test kits with a chemistry analyser (Olympus AU640, Beckman Coulter, Hamburg, Germany).

In each case, we attempted to characterise the virus using peripheral blood leukocytes or brain and spinal cord samples by virus isolation, nested reverse transcriptase polymerase chain reaction (RT-PCR), real-time RT-PCR and sequencing techniques, as described previously (Kutasi et al., 2011).

Table 1. Age, breed, gender characteristics, and sampling sites

\begin{tabular}{lcccc}
\hline Group & Age & Breed & Sex & Sampling site \\
\hline WNV-affected & M: 7.53 years SD: 2.84 & 12 warmbloods & 9 mares & 8 lumbosacral \\
& & 1 pony & 4 geldings & 7 atlanto-occipital \\
Control & M: 8.94 years SD: 3.57 & 16 warmbloods & 10 mares & 12 lumbosacral \\
& & 3 draught horses & 10 geldings & 8 atlanto-occipital \\
& & 1 thoroughbred & \\
\hline
\end{tabular}

M: mean, SD: standard deviation. 
Table 2. Clinical characteristics of the West Nile neuroinvasive disease cases

\begin{tabular}{|c|c|c|c|c|c|c|c|c|c|c|c|c|}
\hline No. & Outcome & $\begin{array}{l}\text { Abnormal } \\
\text { behaviour }\end{array}$ & $\begin{array}{l}\text { Cranial } \\
\text { nerves } \\
\text { affected }\end{array}$ & Hyperaesthesia & $\begin{array}{c}\text { Muscle } \\
\text { fasciculation }\end{array}$ & $\begin{array}{r}\text { Ataxia } \\
1= \\
\text { forelimb } \\
2= \\
\text { hindlimb } \\
3=\text { all }\end{array}$ & $\begin{array}{r}\text { Paresis } \\
1= \\
\text { forelimb } \\
2= \\
\text { hindlimb } \\
3=\text { all }\end{array}$ & Haematology & $\begin{array}{c}\text { Biochemical } \\
\text { parameters } \\
\text { (elevated) }\end{array}$ & $\begin{array}{c}\text { CSF } \\
\text { sampling } \\
\text { site }\end{array}$ & $\begin{array}{l}\text { VNT } \\
\text { on CSF }\end{array}$ & $\begin{array}{c}\text { PCR } \\
(\mathrm{CNS})\end{array}$ \\
\hline 1 & Euthanised & Yes & No & Yes & Yes & $1(3)$ & $1(3)$ & $\begin{array}{l}\text { Leukocytosis, } \\
\text { lymphopenia, } \\
\text { neutrophil } \\
\text { granulocytosis }\end{array}$ & $\begin{array}{l}\text { TP, CK glucose, } \\
\text { lactate }\end{array}$ & $\mathrm{AO}$ & NA & Positive \\
\hline 2 & Euthanised & Yes & Yes & Yes & Yes & $1(3)$ & $1(3)$ & Lymphopenia & glucose, $\mathrm{CK}, \mathrm{LDH}$ & $\mathrm{AO}$ & Negative & Positive \\
\hline 3 & Euthanised & Yes & Yes & Yes & Yes & $1(3)$ & $1(3)$ & $\begin{array}{l}\text { Leukocytosis, } \\
\text { lymphopenia, } \\
\text { neutrophil } \\
\text { granulocytosis }\end{array}$ & glucose, CK, LDH & $\mathrm{AO}$ & Negative & Positive \\
\hline 4 & Euthanised & No & Yes & Yes & Yes & 3 & 3 & Lymphopenia & glucose & AO, LS & NA & Positive \\
\hline 5 & Euthanised & No & No & Yes & Yes & 3 & 3 & Lymphopenia & $\mathrm{TP}$, glucose & $\mathrm{AO}, \mathrm{LS}$ & Negative & Positive \\
\hline 6 & Euthanised & No & Yes & Yes & Yes & $1(3)$ & $1(3)$ & Lymphopenia & $\begin{array}{c}\text { glucose } \mathrm{CK}, \mathrm{LDH}, \\
\text { creatinine }\end{array}$ & $\mathrm{AO}$ & Negative & Positive \\
\hline 7 & Survived & No & Yes & Yes & Yes & 2 & 2 & Negative & $\mathrm{LDH}$ & LS & Negative & NA \\
\hline 8 & Survived & No & Yes & Yes & No & 2 & 2 & Lymphopenia & $\mathrm{CK}, \mathrm{LDH}$ & LS & Positive & NA \\
\hline 9 & Survived & No & Yes & Yes & No & 3 & 2 & Lymphopenia & $\begin{array}{l}\text { TP, glucose, CK, } \\
\text { LDH }\end{array}$ & LS & Positive & NA \\
\hline 10 & Survived & Yes & Yes & Yes & No & 3 & 2 & $\begin{array}{l}\text { Leukocytosis, } \\
\text { lymphopenia, } \\
\text { neutrophil } \\
\text { granulocytosis }\end{array}$ & LDH & LS & Positive & NA \\
\hline 11 & Survived & Yes & Yes & Yes & Yes & 3 & 3 & Lymphopenia & glucose, CK, LDH & $\mathrm{AO}$ & NA & NA \\
\hline 12 & Survived & Yes & Yes & No & Yes & 2 & 2 & NA & NA & LS & NA & NA \\
\hline 13 & Survived & No & Yes & Yes & Yes & 2 & 2 & Lymphopenia & negative & LS & Positive & NA \\
\hline
\end{tabular}

NA: not available, TP: total protein, CK: creatine kinase, LDH: lactate dehydrogenase, CSF: cerebrospinal fluid, AO: atlanto-occipital puncture, LS: lumbosacral puncture, VNT: virus neutralisation test, negative $<1: 2$, positive $>1: 4$, PCR (CNS): polymerase chain reaction on central nervous tissue specimens (all PCRs run on peripheral blood leukocytes were negative). 
The virus neutralisation (VN) test was run in 9 of 13 WNND cases and on all control CSF samples as described by Nagy et al. (2019).

When analysing our results, first we evaluated the normality of our data, i.e. we determined whether parametric or non-parametric statistics should be used. The majority of the data obtained from the WNND cases did not seem to follow normal distribution, and their mean, mode, and median were not close to being equal; hence, the $t$-test based comparison of the means of the diseased and control groups was not feasible. Instead, we opted to establish reference ranges (95\% prediction intervals) based on the control groups and counted the number of cases for each variable that fell outside this range. For the WNND cases we also noted the minimum and maximum values and established the median for each parameter. We used the Wald method and Fisher's exact test to evaluate which measured variables were predictors of the outcome. Finally, Fisher's exact test was applied to establish the relationship between the measured parameters (IBM SPSS Statistics 20 Documentation, United States).

\section{RESULTS}

During the study period we sampled 13 horses affected with WNND. All CSF sampling procedures were performed without any complications. The horses of the control group recovered quickly from the anaesthesia without any sequel. Three horses from the WNV group were euthanized right after the sampling procedure, and three others were euthanised on humane grounds within the next 5 days. Seven horses survived the neuroinvasive disease, of which five had no sequel. All premortem peripheral blood leukocyte samples tested negative for WNV by PCR and all postmortem CNS samples tested positive. Attempts at virus isolation were successful in two cases on postmortem CNS tissues. In all six cases where the disease was identified by means of PCR or virus isolation, the lineage 2 strain was identified (Table 2).

The VN test of the CSF was negative in all control horses and in 5 patients, and positive in 4 WNND horses (Table 2). All the CSF-positive horses and one negative animal survived and in all the other negative horses the disease was fatal.

On macroscopic examination, the CSF was found to be transparent and non-turbid in all control animals and in nine WNV cases and slightly hazy in six WNV cases. Cytological analysis revealed normal cell counts within the reference intervals with exclusively small and large mononuclear cells in all control samples and in samples from three diseased horses. Out of all 15 samples of diseased horses, four had mononuclear pleocytosis and eight had neutrophilic pleocytosis.

We found moderately high total protein and mildly low albumin levels in 53.8 and $75 \%$ of cases, respectively. ALP activities, lactate and glucose concentrations were out of the reference ranges in 91.6, 70 and 50\% of the affected horses, respectively. Table 3 summarises our further findings.

We also determined whether any of the measured variables were good predictors of the outcome (death/survival) of the disease. A noteworthy finding was that none of the six horses with elevated glucose levels survived the disease $(0 / 6$; $\leq 0.36$; modified Wald method with $90 \% \mathrm{CI}$ ) and all of the 6 horses with normal glucose levels survived $(6 / 6 ; \geq 0.64$; modified Wald method with $90 \%$ CI). The dependence of the outcome on the glucose level was also verified with a Fisher's exact test (2-tailed; $P=0.0022)$.

In the two WNV cases where samples were collected using both atlanto-occipital and lumbosacral sampling methods, the results differed depending on the location. The atlanto-occipital CSF sample from horse no. 5 yielded negative results on cytology, the sample contained normal protein but high glucose and lactate levels. The sample obtained by lumbosacral puncture showed lymphocytic pleocytosis, high protein, and higher glucose and lactate levels. In the case of horse no. 4, the lumbosacral sample showed lymphocytic pleocytosis, while the atlanto-occipital sample had more neutrophils with higher protein content, $\mathrm{CK}, \mathrm{LDH}$, and AST activities, and lower urea. Glucose levels were similarly high in both samples. None of these horses survived.

\section{DISCUSSION}

This is the first paper that describes in detail the characteristics of the CSF of horses with WNND caused by a lineage 2 strain and proposes some clues for prognosis and pathogenesis.

The reference ranges set by our control group were consistent with those in previous studies (Mayhew et al., 1977; Andrews et al., 1990; MacWilliams, 2002), except for lactate concentration that was slightly higher and $\mathrm{LDH}$ activity that was moderately higher in our reference group. This could be attributed to the different methodology used by our laboratory.

In previous studies involving human beings, the CSF findings of patients with WNND were non-specific and included pleocytosis (neutrophil or lymphocyte predominance) with elevated protein and normal glucose levels (Tyler et al., 2006). Our findings are very similar to these findings, except that we have found high glucose levels in non-surviving patients. On the other hand, previous reports in horses most commonly found mononuclear pleocytosis with lymphocytic predominance (Wamsley et al., 2001). Although the WNV disease was caused by lineage 1 strains in those cases and lineage 2 strains were responsible in the present report, lineage differences are not likely to be the reason behind these discrepancies. Other studies on human CSF also showed variable data, where patients did not present with the typical lymphocytic pleocytosis, often alluded to when discussing viral meningitis and encephalitis, but rather, most presented with a cerebrospinal fluid neutrophilia (Crichlow et al., 2004; Rawal et al., 2006; Tyler et al., 2006). Previous studies with 
Table 3. Results of cerebrospinal fluid analysis compared to previously published data $\mathrm{a}^{\mathrm{a}, \mathrm{b}, \mathrm{c}}$

\begin{tabular}{|c|c|c|c|c|c|c|c|c|c|c|c|c|c|c|c|c|c|}
\hline & $\begin{array}{r}\text { Inflammatory } \\
\text { proteins } \\
\text { (total- } \\
\text { albumin) }\end{array}$ & $\begin{array}{r}\text { Albumin } \\
(\mathrm{mg} / \mathrm{L})\end{array}$ & $\begin{array}{r}\text { Total } \\
\text { protein } \\
(\mathrm{mg} / \mathrm{L})\end{array}$ & $\begin{array}{r}\text { AST } \\
(\mathrm{IU} / \mathrm{L})\end{array}$ & $\begin{array}{r}\text { ALP } \\
(\mathrm{IU} / \mathrm{L})\end{array}$ & $\begin{array}{r}\text { GGT } \\
\text { (IU/ } \\
\text { L) }\end{array}$ & $\begin{array}{r}\text { Glucose } \\
(\mathrm{mmol} / \mathrm{L})\end{array}$ & $\begin{array}{r}\text { Lactate } \\
(\mathrm{mmol} / \\
\mathrm{L})\end{array}$ & CK (IU/L) & $\begin{array}{r}\mathrm{LDH} \\
(\mathrm{IU} / \mathrm{L})\end{array}$ & $\begin{array}{r}\text { Urea } \\
\text { (mmol/ } \\
\mathrm{L})\end{array}$ & $\begin{array}{r}\mathrm{Na}(\mathrm{mmol} / / \\
\mathrm{L})\end{array}$ & $\begin{array}{r}\mathrm{K} \\
(\mathrm{mmol} / \\
\mathrm{L})\end{array}$ & $\begin{array}{r}\mathrm{Ca} \\
(\mathrm{mmol} / \\
\mathrm{L})\end{array}$ & $\begin{array}{r}\mathrm{Cl} \\
(\mathrm{mmol} / \mathrm{L})\end{array}$ & $\begin{array}{r}\mathrm{P} \\
(\mathrm{mmol} / \\
\mathrm{L})\end{array}$ & $\begin{array}{r}\mathrm{Mg} \\
(\mathrm{mmol} / \\
\mathrm{L})\end{array}$ \\
\hline \multirow[t]{2}{*}{$\begin{array}{l}\text { Literature } \\
\text { references }\end{array}$} & & & $5-100^{\mathrm{a}}$ & $15-50^{\mathrm{a}}$ & & & $\begin{array}{l}1.67- \\
3.89^{a, c}\end{array}$ & $1.92-2.3^{\mathrm{b}}$ & $0-8^{\mathrm{a}, \mathrm{b}, \mathrm{c}}$ & $0-8^{\mathrm{a}, \mathrm{b}}$ & & $140-150^{a, c}$ & $2.5-3.5^{\mathrm{a}, \mathrm{c}}$ & & $95-123^{\mathrm{a}, \mathrm{c}}$ & & \\
\hline & & & $\begin{array}{r}20-124^{\mathrm{b}} \\
20-80^{\mathrm{c}}\end{array}$ & $\begin{array}{l}0-16^{b} \\
7-24^{c}\end{array}$ & & & $\begin{array}{l}\begin{array}{l}30-70 \% \text { of } \\
\text { blood } \\
\text { glucose }^{\mathrm{b}}\end{array}\end{array}$ & & & & & & & & & & \\
\hline $\begin{array}{l}\text { Our reference } \\
\text { range (based } \\
\text { on the control } \\
\text { group) }\end{array}$ & $0-56$ & $10-50$ & $32.16-75.55$ & $6.0-14.0$ & $0.1-3.5$ & $0-4.0$ & $\begin{array}{c}2.54- \\
3.81\end{array}$ & $1.89-3.07$ & $0-4.6$ & $14.7-44.1$ & $4.6-8.8$ & $140-151.8$ & $2.8-3.1$ & $1.13-1.41$ & $113-128.2$ & $0.02-0.38$ & $0.53-1.34$ \\
\hline Median & 28.5 & 20 & 45.15 & 10.25 & 1.7 & 0.9 & 2.875 & 2.455 & 2.675 & 26.2 & 6.7 & 144.45 & 2.9 & 1.26 & 122.3 & 0.295 & 0.885 \\
\hline $\begin{array}{l}\text { Minimum- } \\
\text { maximum } \\
\text { WNND group }\end{array}$ & $0-110$ & $0-27$ & $40.4-210.0$ & $7-20.9$ & $1.2-14.1$ & $0-2$ & $\begin{array}{c}2.52- \\
5.8\end{array}$ & $1.93-6.64$ & $1.4-63$ & 10-111.6 & $3.5-6.7$ & $123-148.4$ & $2.7-3.1$ & $1.11-1.34$ & 109-147 & $0.2-0.85$ & $0.51-1.75$ \\
\hline Median & 64 & 10 & 90.6 & 11.6 & 9.0 & 1.1 & 3.21 & 3.85 & 8.0 & 43 & 4.7 & 140 & 2.9 & 1.24 & 119 & 0.32 & 1.03 \\
\hline $\begin{array}{l}\text { Number of } \\
\text { WNND horses } \\
\text { with normal } \\
\text { values }\end{array}$ & 4 & 3 & 6 & 6 & 1 & 12 & 6 & 3 & 5 & 6 & 9 & 8 & 11 & 6 & 7 & 9 & 7 \\
\hline $\begin{array}{l}\text { Number of } \\
\text { WNND horses } \\
\text { with abnormal } \\
\text { values }\end{array}$ & 8 & 9 & 7 & 6 & 11 & 0 & 6 & 7 & 7 & 6 & 3 & 4 & 1 & 0 & 5 & 3 & 5 \\
\hline
\end{tabular}

Note that inflammatory protein is a calculated value based on the total protein and albumin levels.

WNND: West Nile neuroinvasive disease; AST: aspartate aminotransferase; ALP: alkaline phosphatase; GGT: gamma-glutamyltransferase; CK: creatine kinase; LDH: lactate dehydrogenase; Na: sodium, K: potassium, Ca: calcium, Cl: chloride, P: phosphate, Mg: magnesium.

${ }^{a}$ Mayhew et al. (1977).

bAndrews et al. (1990).

${ }^{\mathrm{c}}$ MacWilliams (2002). 
mice suggest that neutrophils are the predominant immune cells that are initially and rapidly recruited to the sites of infection with WNV (Lim et al., 2011). According to a study involving human patients (Rawal et al., 2006), the mean total leukocyte counts and mean neutrophil fractions were greater in samples collected within the first three days of the clinical signs than in those collected beyond day 3. Sampling time might also be responsible for the different findings. The samples were collected from most of our horses relatively early in the disease process (in all horses within 5 days and in 8 within 3 days of the onset of clinical signs). According to an early study about CSF in equine patients, the presence of neutrophils strongly suggests meningitis (Beech, 1983). Different severity and involvement of the meningeal inflammation could also explain the variable cytological findings. In another study, it was found that older patients with WNV were more likely to have neutrophils in their CSF (Jordan et al., 2012). The average age of our patients with high neutrophil numbers was 8 years (4-13 years) and of those with mononuclear pleocytosis was 6.6 years (4-9 years). Furthermore, neutrophil-related proteins were found at higher levels in the CSF of patients with WNND, underlining the likely key role played by neutrophils in the development of the inflammatory response and brain damage (Fraisier et al., 2014). We have also found that CSF neutrophilia is more likely to be found in parallel with high protein content. The measured data indicated that neutrophilic pleocytosis in the CSF was more likely in cases with high total protein content (Fisher's exact test; 2-tailed; $P=0.1026$ ). In case when the calculated $P$ value was $\sim 0.1$, our data could not be regarded as a definitive proof of the dependence of the classification. However, we decided that the value was low enough so that the observed dependence was worth pointing out to the reader. The increase in protein could reflect the increase of endothelial cell permeability, which would indicate that the blood-brain barrier is damaged in WNV patients. The level of albumin was lower in most cases and that of total protein was high, suggesting the presence of increased inflammatory proteins like globulins in the CSF of diseased animals. It is difficult to distinguish whether viral or immunemediated neuronal injury is more significant in a disease process, and probably because of the low sample number we were unable to demonstrate any relationship between the protein levels, the presence of neutrophils and the outcome.

We detected normal or high CSF glucose concentrations similar to the findings of a study on seasonal human epidemic WNV meningoencephalitis (Rawal et al., 2006). Cerebrospinal glucose concentrations might reflect changes in blood glucose which could be elevated because of critical illness causing a stress response (Andrews et al., 1990; Seehusen et al., 2003). Human and animal studies suggest that this is not a benign condition and that stress-induced hyperglycaemia is associated with a high risk of mortality (Capes et al., 2001; Guo et al., 2014). Increased lactate levels were found in most of the cases as well increased LDH levels in half of the samples in the WNV-affected group. L-lactate is formed during normal anaerobic glycolysis by interconversion from pyruvate via the actions of $\mathrm{LDH}$. Lactate concentrations in the CSF largely represent its production by the brain but it is also increased in case of low glucose concentrations to meet the energy requirements via the anaerobic pathway (Irani, 2009). Hypoglycaemia was not seen in our cases. Increase in CSF lactate concentration reportedly occurs with bacterial infections but not with nonseptic meningitis (Schwarz and Piercy, 2006). On the other hand, an increase in the level of CSF lactate also occurs with any condition that results in reduced brain oxygenation and/ or increased intracranial pressure. CNS tissue hypoxia could be the result of inflammatory processes secondary to WNV infection. The potential influence of ketamine use on brain energy metabolism was considered, but when looking at the results of the control group, this was excluded. Ketamine has been shown to increase brain lactate concentration in rats and glucose levels in mouse brain (McLoughlin et al., 1987). In the control group, horses undergoing general anaesthesia had slightly lower glucose $(2.89 \pm 0.186$ vs. $3.11 \pm 0.445)$ and lactate $(2.37 \pm 0.237$ vs. $2.81 \pm 0.729)$ concentrations than horses sampled standing.

As most enzymes are relatively large molecules, there is very little diffusion of enzymes across the intact and normal blood-CSF barrier and increased activities of the enzymes in the CSF are assumed to be facilitated by the cells within the CNS (Furr, 2008). The potential sources of increased enzyme activity in the WNV group horses are inflammatory cells or the damaged nerve cells and myelin. Recently, it has been shown that WNV induced the expression of interleukin- $1 \beta$, $-6,-8$, and tumour necrosis factor- $\alpha$, where neurons were one of the potential sources of pro-inflammatory cytokines, and these pro-inflammatory mediators were one of the main factors driving WNV-induced neurotoxicity, cell death and CNS tissue damage (Lim et al., 2011). Based on previous histologic findings of WNV encephalitis, namely perivascular inflammation, microgliosis, variable degree of necrosis and loss of neurons, it is less likely that the source of increased enzymes is secondary to a damaged blood-brain barrier or blood-CSF barrier and increased leakage from the plasma.

The most reliable parameter was the increase in the activity of the enzyme alkaline phosphatase. The CSF of patients without neurological disorders contains little or no activity as it was also shown in our control group (McComb et al., 1979). According to a previous human study, the CSF alkaline phosphatase activities of patients with meningitis and other neurological disorders varied in direct correlation with the number of polymorphonuclear leukocytes present and with the protein concentration (McComb et al., 1979). We could not demonstrate a clear relationship between the number of neutrophils, the level of protein, and alkaline phosphatase activity. The reason behind this might have been the low sample number.

There is surprisingly very little information about urea levels in the normal CSF although an increase would be 
significant in differentiating uraemic encephalopathy. Since urea is readily diffusible, the urea levels should be parallel to those found in the serum (Irani, 2009). Decreased urea levels in some of our patients' samples could be secondary to reduced hepatic synthesis of urea from ammonia in case of severe systemic disease. None of our patients had increased urea concentration in their CSF.

The electrolyte composition of the CSF has been sparsely reported, but in general, the concentrations of sodium and chloride in the CSF are similar or slightly higher, those of potassium in the CSF are similar or slightly lower, and those of magnesium in the CSF are slightly higher than those in the serum (Mayhew et al., 1977; MacWilliams, 2002). Our reference ranges based on the control group were concordant with the results previously published. In some of the $\mathrm{WNV}$-affected horses, low sodium and increased magnesium concentrations were detected. These electrolyte abnormalities can originate from the cellular damage in the CNS, where intracellular solutes may leak out of the cell because of increased membrane permeability and lead to the redistribution of sodium and increased magnesium. In studies involving humans, phosphate was found in the normal CSF at levels of $50-60 \%$ of the expected serum concentration and it has also been observed previously that inorganic phosphate concentrations in the CSF increase in direct proportion to total CSF protein levels (Irani, 2009). Although we found increased inorganic phosphate concentration in three cases, a similar relationship could not be demonstrated.

When we collected samples from both lumbosacral and atlanto-occipital sites from the same patient, we obtained different results. This can be attributed to the different locations of the more severe CNS damage causing more significant alterations in the sample collected from the site closer to the area of damage. Although there is a synchronous appearance of WNV at many sites in the brain and spinal cord, and pathological alterations can be detected in many parts of the CNS, the severity of these damages can differ, also reflected in the clinical signs and disease progression. On the other hand, the values of certain parameters differ depending on sampling sites even in healthy horses because of differences in the blood-CSF permeability and flow rates between the atlanto-occipital and lumbar regions (Vernau et al., 2008).

We must note that although neutralisation test of the sera to detect specific antibodies is the gold standard of antemortem diagnosis of WNV infection (Long and Barr, 2018), the same does not apply to the CSF. A negative VN test on the CSF does not rule out WNV infection. It is of interest, but statistically not examined because of the low sample number, that horses without detectible neutralising antibodies in the CSF were less likely to survive. Increased risk for fatality in these cases might be explained by the weak or absent intrathecal antibody production.

Based on our results, CSF sampling facilitates the differential diagnosis. Contrary to our findings in horses with WNND, CSF samples from patients with equine herpesvirus myeloencephalopathy typically show xanthochromia and have increased total protein concentrations (principally albumin) without a concomitant increase in cell count (Pusterla et al., 2009). Horses with rabies have slightly elevated total cell count, with a predominance of lymphocytes and occasionally increased protein concentration in their CSF (Green et al., 1992). So far it was believed that neutrophilic CSF analysis in patients with suspected viral encephalitis was suggested to be typical of Alphaviruses, rather than WNV (Wamsley et al., 2001). Neutrophilia might be misleading in some cases but Alphaviruses causing neurologic disorders in horses, like Eastern, Western and Venezuelan equine encephalomyelitis viruses, are non-endemic in Europe. CSF changes resulting from the migration of parasites are xanthochromia, an increase in protein concentration, and a slight mononuclear, eosinophilic or, in terminal phases, neutrophilic pleocytosis (Mayhew et al., 1978; Darien et al., 1988). These findings except eosinophilia and xanthochromia might be overlapping. Bacterial meningitis causes xanthochromia, moderate to marked suppurative inflammation and increased protein and lactate in the CSF (Toth et al., 2012). Cervical stenotic myelopathy does not result in obvious alterations of the CSF.

CSF analysis provides a general index of neurological health and often provides evidence of the presence of a specific disease. Similar to a complete blood count, CSF analysis has reasonable sensitivity but low specificity. The CSF findings of patients with WNND are nonspecific and variable and possibly depend on the age of the patient, the sampling time, the site of sampling and previous treatments. Neutrophils likely play a role in the development of inflammatory response and brain damage, but further examinations would be required to fully elucidate their role in the pathogenesis of WNND. Increased enzyme activities and changes in the electrolyte concentrations reflect CNS cellular injury rather than blood-brain barrier damage. A higher sample number would be required to demonstrate the relationship between inflammation, CNS damage, and changes of the CSF parameters. Although elevated glucose levels reliably predicted the outcome, based on the observation that all non-surviving patients had high plasma glucose levels as well, these results might be secondary to increased plasma levels and reflect general stress or serious illness rather than any CNS pathophysiology. Based on all these findings, examination of the CSF is most useful when the results are correlated with the history, the clinical findings and the results of ancillary laboratory tests.

\section{ACKNOWLEDGEMENT}

We would like to thank Dr. Dániel Joó PhD for the statistical analysis, Dr. Kinga Joó DVM for data handling and Dr. Blanka Hargitai DVM for her contribution in the sample collection. We would also like to thank the support of the Bolyai Grant and TÉT-Balaton Grant (NKFI). The project is supported by the European Union and co-financed by the European Social Fund (grant agreement no. EFOP-3.6.3- 
VEKOP-16-2017-00005, project title: 'Strengthening the scientific replacement by supporting the academic workshops and programs of students, developing a mentoring process').

\section{REFERENCES}

Andrews, F. M., Matthews, H. K. and Reed, S. M. (1990): The ancillary techniques and tests for diagnosing equine neurologic disease. Vet. Med. 85, 1325-1330.

Bakonyi, T., Ferenczi, E., Erdélyi, K., Kutasi, O., Csörgö, T., Seidel, B., Weissenböck, H., Brugger, K., Bán, E. and Nowotny, N. (2013): Explosive spread of a neuroinvasive lineage 2 West Nile virus in Central Europe, 2008/2009. Vet. Microbiol. 26, 61-70.

Beech, J. (1983): Cytology of equine cerebrospinal fluid. Vet. Pathol. 20, 553-562.

Capes, S. E., Hunt, D., Malmberg, K., Pathak, P. and Gerstein, H. C. (2001): Stress hyperglycemia and prognosis of stroke in nondiabetic and diabetic patients: a systematic overview. Stroke 32, 2426-2432.

Crichlow, R., Bailey, J. and Gardner, C. (2004): Cerebrospinal fluid neutrophilic pleocytosis in hospitalized West Nile virus patients. J. Am. Board Fam. Pract. 17, 470-472.

Darien, B. J., Belknap, J. and Nietfeld, J. (1988): Cerebrospinal fluid changes in two horses with central nervous system nematodiasis (Micronema deletrix). J. Vet. Intern. Med. 2, 201-205.

Fraisier, C., Papa, A., Granjeaud, S., Hintzen, R., Martina, B., Camoin, L. and Almeras, L. (2014): Cerebrospinal fluid biomarker candidates associated with human WNV neuroinvasive disease. PloS One 9, e93637.

Furr, M. (2008): Cerebrospinal fluid and the blood brain barrier. In: Furr, M. and Reed, S. (eds.) Equine Neurology, 2nd ed. Blackwell Publishing, USA. pp. 21-36.

Green, S. L., Smith, L. L., Vernau, W. and Beacock, S. M. (1992): Rabies in horses: 21 cases (1970-1990). J. Am. Vet. Med. Assoc. 200, 1133-1137.

Guo, Y.-J., Zhou, Y., Zhang, S.-Y., Wei, Q., Huang, Y., Xia, W. Q. and Wang, S. H. (2014): Optimal target range for blood glucose in hyperglycaemic patients in a neurocritical care unit. Diabetes Vasc. Dis. Res. 11, 352-358.

Irani, D. N. (2009): Properties and composition of normal cerebrospinal fluid. In: Irani, D. N. (ed.) Cerebrospinal Fluid in Clinical Practice. Elsevier Health Sciences, USA. pp. 69-93.

Jordan, M., Nagpal, A., Newman, W., Thompson, P. A. and Carson, P. J. (2012): Plasma cell cerebrospinal fluid pleocytosis does not predict West Nile virus infection. J. Biomed. Biotechnol. 2012, 697418.

Kutasi, O., Bakonyi, T., Lecollinet, S., Biksi, I., Ferenczi, E., Bahuon, C., Sardi, S., Zientara, S. and Szenci, O. (2011): Equine encephalomyelitis outbreak caused by a genetic lineage 2 West Nile virus in Hungary. J. Vet. Intern. Med. 25, 586-591.

Lim, S. M., Koraka, P., Osterhaus, A. D. and Martina, B. E. (2011): West Nile virus: immunity and pathogenesis. Viruses 3, 811828.
Long, M. T. and Barr, K. L. (2018): Interpretation of testing for common mosquito transmitted diseases: West Nile virus and Eastern and Western equine encephalitis. In: Pusterla, N. and Higgins, J. (eds.) Interpretation of Equine Laboratory Diagnostics, 1st ed. Wiley Blackwell, USA. pp. 157-165.

MacWilliams, P. S. (2002): Cerebrospinal fluid. In: Cowel, R. L. and Tyler, R. D. (eds.) Diagnostic Cytology and Hematology of the Horse, 2nd ed. Mosby, USA. pp. 171-179.

Mayhew, I. G., deLahunta, A., Whitlock, R. H., Krook, L. and Tasker, J. B. (1978): Spinal cord disease in the horse. Cornell Vet. 68(Suppl. 6), 1-207.

Mayhew, I. G., Whitlock, R. H. and Tasker, J. B. (1977): Equine cerebrospinal fluid: reference values of normal horses. Am. J. Vet. Res. 38, 1271-1274.

McComb, R. B., Bowers, G. N. and Posen, J. R. (1979): Clinical utilization of alkaline phosphatase measurements. In: McComb, R. B., Bowers, G. N. and Posen, J. R. (eds.) Alkaline Phosphatase. Plenum Press, New York. pp. 289-372.

McLoughlin, J. V., Wheatley, A. M. and Wilson, P. (1987): The effect of anaesthetics on the concentration of creatine phosphate, adenosine triphosphate and lactate in brain and skeletal muscle of the rat. J. Comp. Pathol. 97, 341-349.

Nagy, A., Szöllösi, T., Takács, M., Magyar, N. and Barabás, É. (2019): West Nile virus seroprevalence among blood donors in Hungary. Vector Borne Zoonotic Dis. 19, 844-850.

Pusterla, N., Wilson, W. D., Madigan, J. E. and Ferraro, G. L. (2009): Equine herpesvirus-1 myeloencephalopathy. A review of recent developments. Vet. J. 180, 279-289.

Rawal, A. L., Gavin, P. J. and Sturgis, C. D. (2006): Cerebrospinal fluid cytology in seasonal epidemic West Nile virus meningoencephalitis. Diagn. Cytopathol. 34, 127-129.

Schwarz, B. and Piercy, R. J. (2006): Cerebrospinal fluid collection and its analysis in equine neurological disease. Equine Vet. Educ. 18, 243-248.

Seehusen, D. A., Reeves, M. M. and Fomin, D. A. (2003): Cerebrospinal fluid analysis. Am. Fam. Phys. 68, 1103-1108.

Shahim, P., Mansson, J. E., Darin, N., Zetterberg, H. and Mattsson, N. (2013): Cerebrospinal fluid biomarkers in neurological diseases in children. Eur. J. Paediatr. Neurol. 17, 7-13.

Smithburn, K. C., Hughes, T. P., Burke, A. W. and Paul, J. H. (1940): A neurotropic virus isolated from the blood of a native of Uganda. Am. J. Trop. Med. 20, 471-492.

Szentpáli-Gavallér, K., Antal, L., Tóth, M., Kemenesi, G., Soltész, Z., Dán, Á., Erdélyi, K., Bányai, K., Bálint, Á., Jakab, F. and Bakonyi, T. (2014): Monitoring of West Nile virus in mosquitoes between 2011-2012 in Hungary. Vector Borne Zoonotic Dis. 14, 648-655.

Toth, B., Aleman, M., Nogradi, N. and Madigan, J. E. (2012): Meningitis and meningoencephalomyelitis in horses: 28 cases (1985-2010). J. Am. Vet. Med. Assoc. 240, 580-587.

Tyler, K. L., Pape, J., Goody, R. J., Corkill, M. and KleinschmidtDeMasters, B. K. (2006): CSF findings in 250 patients with serologically confirmed West Nile virus meningitis and encephalitis. Neurology 66, 361-365.

Vernau, W., Vernau, K. A. and Bailey, C. S. (2008): Cerebrospinal fluid. In: Kaneko, J. J., Harvey, J. W. and Bruss, M. L. (eds.), 
Clinical Biochemistry of Domestic Animals, 6th ed. Elsevier Inc., USA. pp. 769-819.

Wamsley, H. L., Alleman, A. R., Porter, M. B. and Long, M. T. (2001): Findings in cerebrospinal fluids of horses infected with West Nile virus: 30 cases. J. Am. Vet. Med. Assoc. 221, 1303-1305.
Ziegler, U., Lühken, R., Keller, M., Cadar, D., Grinten, E., Friederike, M., Albrecht, K., Eiden, M., Rinder, M., Lachmann, L., Höper, D., Vina-Rodriguez, A., Gaede, W., Pohl, A., SchmidtChanasit, J. and Groschup, M. H. (2018): West Nile virus epizootic in Germany, 2018. Antivir. Res. 162, 39-43. 